\title{
Comparison of passive microwave remote-sensing snow-depth products on Arctic sea ice
}

\author{
Chenlei Zhang ${ }^{1}$, Qing Ji' ${ }^{1}$ Xiaoping Pang ${ }^{1,2}$, Jie Su³ \& Chang Liü \\ ${ }^{1}$ Chinese Antarctic Center of Surveying and Mapping, Wuhan University, Wuhan, China; \\ ${ }^{2}$ School of Resource and Environmental Sciences, Wuhan University, Wuhan, China; \\ ${ }^{3}$ Key Laboratory of Physical Oceanography, Ministry of Education, Ocean University of China, Qingdao, China
}

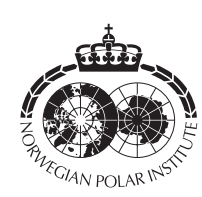

\begin{abstract}
Changes in snow cover on the surface of Arctic sea ice affect the energy balance between the atmosphere and the ocean and play a vital role in the global climate system. Accurate snow depth is a precondition for representing thermodynamic processes in sea-ice systems and is helpful for estimating sea-ice thickness. To better apply Arctic snow-depth products released by different organizations, we compared four kinds of snow-depth products based on three kinds of passive microwave (PM) sensors and evaluated them against the snow depth measured by ice mass-balance buoys (IMB snow depth) and Operation Ice Bridge airborne snow radar (OIB snow depth). The results show that the snow depths from the product released by the University of Bremen (UB) are larger than those by the National Snow and Ice Data Center (NSIDC) and National Aeronautics and Space Administration (NASA), with an average difference of $10 \mathrm{~cm}$. Comparing the PM remote-sensing snow depths released by UB, NSIDC and NASA against IMB and OIB snow depths, it is found that NSIDC AMSR-E snow-depth product has the highest accuracy. Although these PM remote-sensing snow-depth products released by different organizations differ in accuracy, they all reflect the spatio-temporal variation characteristics of snow depth on Arctic sea ice. These comparisons and analysis of snow-depth products from different sensors released by different organizations provide a basis for further investigation of Arctic sea-ice thickness estimation and benefit the studies of Arctic sea ice and climate change.
\end{abstract}

Keywords

Cryosphere; snow cover; ice mass-balance buoys; ice bridge; accuracy analysis; sea-ice thickness

\section{Correspondence}

Qing Ji, Chinese Antarctic Center of Surveying and Mapping, Wuhan University, Wuhan 430079, China. E-mail: jiqing@whu. edu.cn

\begin{abstract}
Abbreviations
AMSR-E: Advanced Microwave Scanning Radiometer on NASA's Earth Observing System Aqua Spacecraft; ASI: Arctic Radiation and Turbulence Interaction Study Sea Ice (concentration algorithm); CRREL: US Army Cold Regions Research and Engineering Laboratory; IMB: ice mass-balance buoy; MAD: mean absolute deviation; NASA: US National Aeronautics and Space Administration; NT: NASA Team; NT2: NASA Team 2; NSIDC: National Snow and Ice Data Center, Boulder, CO; OIB: Operation Ice Bridge; PM: passive microwave; RMSD: root mean square deviation; SSM/I: Special Sensor Microwave/ Imager, a PM radiometer system on board US Air Force Defense Meteorological Satellite Program satellites; SSMIS: Special Sensor Microwave Imager/ Sounder, a PM radiometer system on board US Air Force Defense Meteorological Satellite Program satellites; SMMR: Scanning Multichannel Microwave Radiometer, a microwave radiometer on board of the Seasat and Nimbus 7 satellites, succeeded by the SSM/l; UB: University of Bremen; W99: Climatological Snow-Depth Model developed by Warren et al. (1999)
\end{abstract}

\section{Introduction}

In the Arctic, sea ice shapes ecosystems and human activities. The Arctic has been undergoing rapid changes in recent decades, with sea ice decreasing in extent and thickness at an accelerating rate (Nghiem et al. 2007; Kwok \& Cunningham 2008), transforming from thick, multi-year ice to thin, first-year ice (Maslanik et al. 2011). The Arctic sea-ice loss has contributed to the observed Arctic warming amplification and to the cooling trends over Eurasia (Ogawa et al. 2018). Snow on sea ice regulates our planet's energy balance, reflecting $85 \%$ of incoming solar radiation back into space (Webster et al. 2018). The change in overlying snow cover affects the energy exchange between the atmosphere, snow, ice and ocean (Brucker \& Markus 2013), which has a significant impact on sea-ice thickness and volume (Perovich et al. 2007; Mäkynen \& Similä 2015).

The fifth assessment report of the Intergovernmental Panel on Climate Change pointed out that the study of snow depth on Arctic sea ice has become an urgent issue (Stocker et al. 2013). The growth and melting of sea 
ice are influenced by the snow load (Blazey et al. 2013; Riche \& Schneebeli 2013) because of the heat insulation provided by snow. Among other things, we require a better understanding of the inter-decadal variation of snow depth on Arctic sea ice. Comiso (2012) and Stroeve et al. (2012) analysed large amount of snow-depth data acquired from Soviet drifting ice stations between 1954 and 1991, which indicated that Arctic sea ice decreased greatly because of the increasing absorption of solar radiation by the snow. Warren et al. (1999) established a climatological snow-depth model (W99) that could be used to calculate climatological monthly snow depth on Arctic sea ice. Since then, the snow depths from W99 have been widely used in the studies of sea ice and global change.

However, W99 snow depth ignored the inter-annual variations in snow on Arctic sea ice. With the rapid ongoing changes in Arctic sea ice, our knowledge of snow depth on Arctic sea ice has become more and more urgent. NASA has been carrying out the OIB airborne observation mission for the Arctic since 2009. Using the OIB snow-depth observation data, Webster et al. (2014) found that the snow depth in the northern Arctic had reduced by more than 10 $\mathrm{cm}$ compared to the in situ measurements at the Soviet drifting stations. In recent years, the snow depth on Arctic sea ice observed by the IMBs has been released by CRREL. CRREL has provided valuable snow-depth measurements by buoys since 2001, but only limited information on the first-year sea ice (Lei et al. 2017). In situ snow-depth measurements are sparse in time and space due to the limitations imposed by the harsh Arctic environment.

With the development of satellite remote-sensing technology, PM remote sensing provides a good tool to retrieve snow depth on Arctic sea ice at a large scale. Markus \& Cavalieri (1998) first used the brightness temperature measured by SSM/I to retrieve snow depth on Antarctic sea ice. Then, the AMSR-E measured brightness temperatures were converted to SSM/I-equivalent brightness temperatures by Comiso et al. (2003). Therefore, Markus \& Cavalieri's (1998) algorithm is suitable for the retrieval of snow depth based on the AMSR-E. Since then, many research organizations have released snow-depth products based on these PM remote sensors' measurements. However, the differences between these snow-depth products and the accuracy of the retrieved snow depth based on different PM sensors require further investigation.

In this study, we compared four PM remote-sensing snow-depth products provided by the UB, NSIDC and NASA, and validated these products using OIB and IMB snow-depth measurements. The aim of this study is to analyse the difference of different snow-depth products to better apply these products in further research on sea ice and climate change.

\section{Data and methods}

\section{SSM/I and SSMIS snow-depth products}

The first kind of snow-depth products on Arctic sea ice used for comparison were retrieved from the sensors of SSM/I, produced by NASA (https://neptune.gsfc.nasa. gov/csb/index.php?section=53), and SSMIS, produced by UB (https://seaice.uni-bremen.de/data/ssmis/snow_day$\operatorname{grid} /$ ). Both the NASA SSM/I and the UB SSMIS products adopt the snow-depth algorithm proposed in Markus \& Cavalieri (1998) and follow the following equation:

$$
h_{s}=\alpha_{1}+\alpha_{2} G R V_{(19 V 37 V)} \text {, }
$$

where $h_{\mathrm{s}}$ (in $\mathrm{cm}$ ) is the snow depth, $\alpha_{1}$ and $\alpha_{2}$ are coefficients obtained by linear regression using in situ snow-depth measurements and the calculated $C$ from PM observations. The mentioned snow-depth retrieval algorithm is based on the spectral gradient ratio between $19.4 \mathrm{GHz}$ and $37.0 \mathrm{GHz}$ at vertical polarization, which is $G R V_{(19 \mathrm{v} 37 \mathrm{~V})}$ (Comiso et al. 2003). Emanated microwave radiances by the snow-ice interface (which is a typical emitting layer of Arctic sea ice at frequencies below $50 \mathrm{GHz}$ ) are attenuated within the snow layer. However, the intensity of attenuation is directly related to the frequency. Generally, extinction by snow scattering becomes larger when frequency increases, leading to measured radiance being smaller at higher frequencies. So, thick snow depth reduced $G R V_{(19 \mathrm{v} 37 \mathrm{~V})}$ (Lee, Sohn \& Shi 2018; Rostosky et al. 2018). For SSM/I and SSMIS sensors, $\alpha_{1}$ and $\alpha_{2}$ are -2.34 and -771 , respectively, and $G R V_{(19 \mathrm{v} 37 V)}$ is the vertical gradient ratio, calculated by the following equation (Brucker \& Markus 2013):

$$
G R V_{(19 V 37 V)}=\frac{\left[T_{b}(37 V)-T_{b}(19 V)-k_{1}(1-C)\right]}{\left[T_{b}(37 V)+T_{b}(19 V)-k_{2}(1-C)\right]},
$$

where, $k_{1}=T_{(b o)}(37 V)-T_{(b o)}(19 V), k_{2}=T_{(b o)}(37 V)+T_{(b o)}(19 V)$, $T_{(b o)^{\prime}}$ the open-water brightness temperature observed at different frequency (37 GHz or $19 \mathrm{GHz}$ ) is the tie point value from open-water samples, and is used as a constant, and $C$ is the sea-ice concentration.

The sea-ice concentration is an important parameter for the remote-sensing retrieval of snow depth. Different organizations make use of different sea-ice concentration algorithms. UB adopts the ASI concentration algorithm (Spreen et al. 2008), while NASA uses the NT sea-ice concentration algorithm (Markus \& Cavalieri 1998).

The period covered by the UB SSMIS snow-depth product spans from 8 March 2011 to 15 April 2014, with 988 days data, while the period covered by the NASA SSM/I snow-depth product is from 3 November 1978 to 
28 February 2017, with 11675 days data. It should be noted that the first period of NASA snow-depth product was retrieved from the SMMR (1978-1987). Moreover, the spatial resolution of the UB SSMIS snow-depth product is $6.25 \mathrm{~km}$, while that of the NASA SSM/I product is $25 \mathrm{~km}$. An example of the snow-depth products of UB SSMIS and NASA SSM/I with a spatial resolution of $12.5 \mathrm{~km}$ on 15 March 2011 is shown in Fig. 1.

\section{AMSR-E snow-depth products}

Snow depth on Arctic sea ice can also be calculated from the brightness temperature data observed by AMSR-E. Compared with previous microwave radiometers, AMSR-E has a higher spatial resolution and wider measurement range of radiation. Two AMSR-E snow-depth products were used for comparison in this study: one produced by UB (https:// seaice.uni-bremen.de/data/amsre/snow_daygrid/) and the other by the NSIDC (http://nsidc.org/data/AE_SI12). As for the snow-depth retrieval from AMSR-E, it should be noted that the linear regression coefficients (Eqn. 1) of $\alpha_{1}$ and $\alpha_{2}$ are 2.9 and -782 respectively (Brucker $\delta$ Markus 2013). The sea-ice concentration algorithm adopted by UB is the ASI algorithm, while NSIDC uses the enhanced NT2 sea-ice concentration algorithm (Comiso et al. 2003).
The AMSR-E snow-depth products of UB and NSIDC cover the same period from l June 2002 to 4 October 2011, which is also the effective lifetime of the AMSR-E sensor's operation. During this period, these two daily snow-depth products have a different number of days of valid data, with the UB product having 3328 days altogether, while the NSIDC has 3182 days. The UB product provides snow-depth data with two resolutions of $6.25 \mathrm{~km}$ and $12.5 \mathrm{~km}$, while NSIDC provides them only with a resolution of $12.5 \mathrm{~km}$. For the purpose of data comparison in this study, all data were re-sampled to $12.5 \mathrm{~km}$ resolution using the nearest neighbour interpolation method and the accuracy did not change after scale-effect tests. Figure 2 shows an example of the AMSR-E snow-depth products from UB and NSIDC with the spatial resolution of $12.5 \mathrm{~km}$ on 15 March 2011.

\section{OIB and IMB snow-depth observational data}

In addition to comparing the snow-depth products derived from different PM sensors produced by different organizations described above, we also compared and validated these snow-depth products against the OIB and IMB observational data.

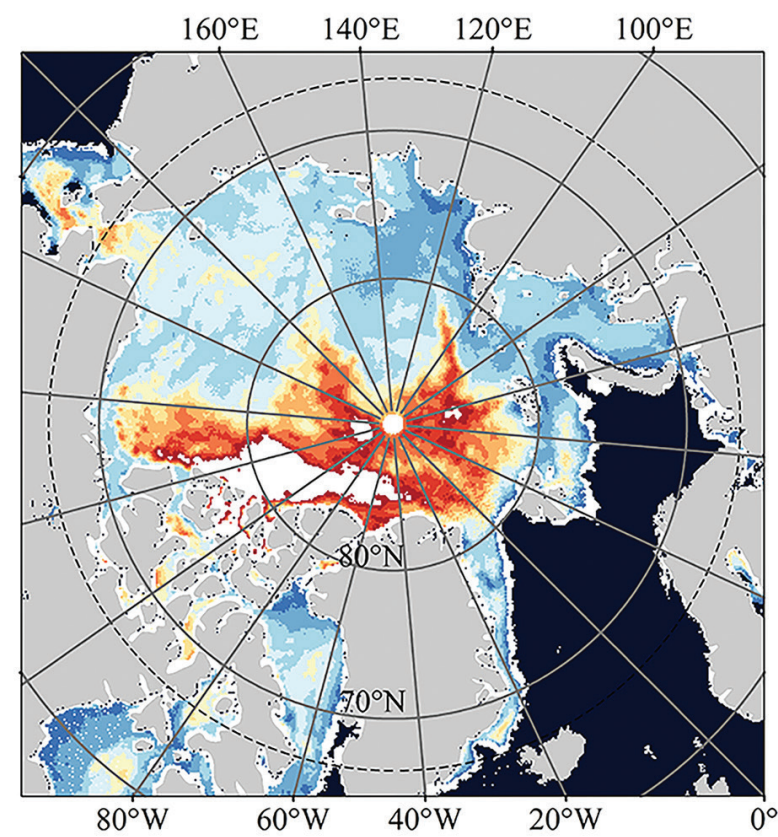

(a) UB SSMIS 2011.3.15

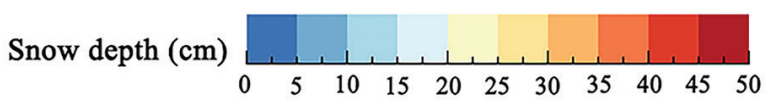

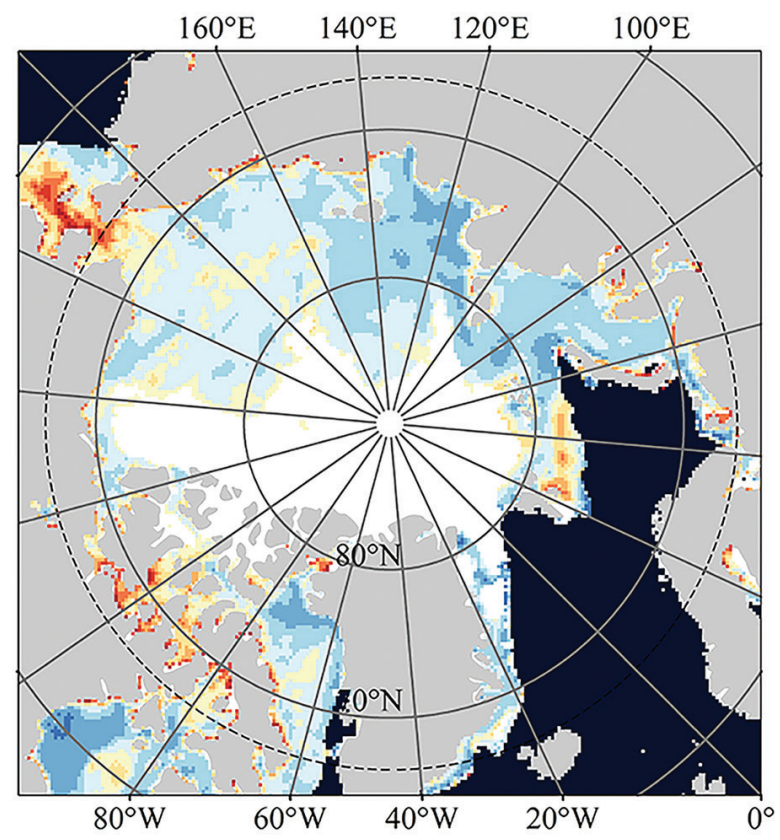

(b) NASA SSM/I 2011.3.15

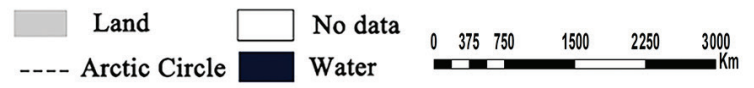

Fig. 1 Daily spatial distribution of snow depth on Arctic sea ice on 15 March 2011 calculated from (a) SSMIS brightness temperature produced by UB, and (b) SSM/l brightness temperature produced by NASA. 


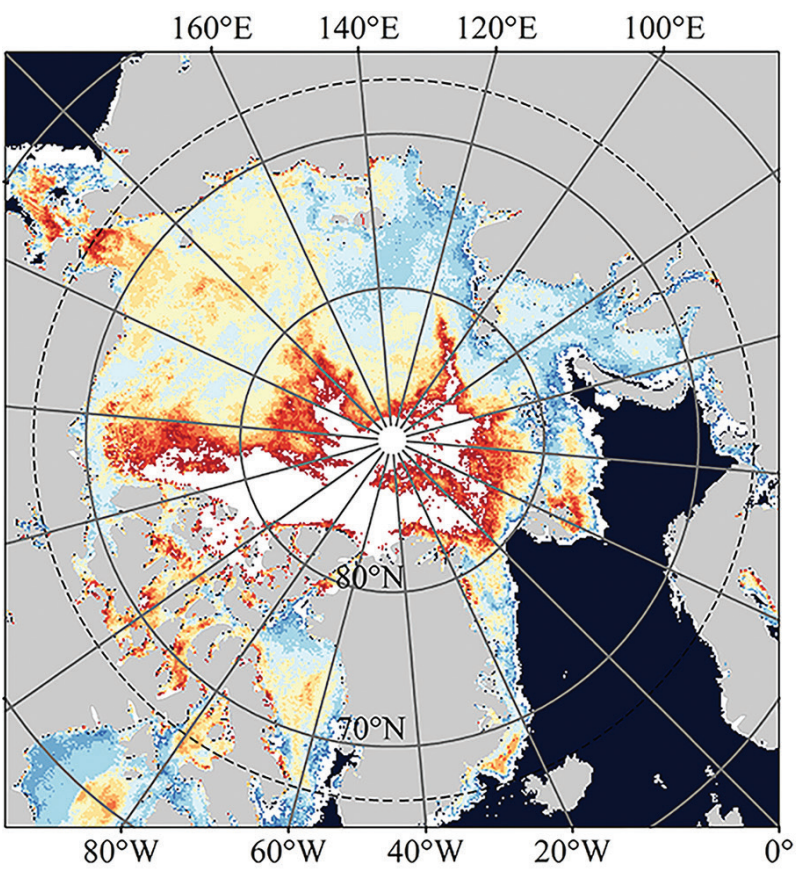

(a) UB AMSR-E 2011.3.15

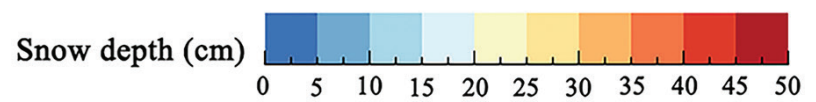

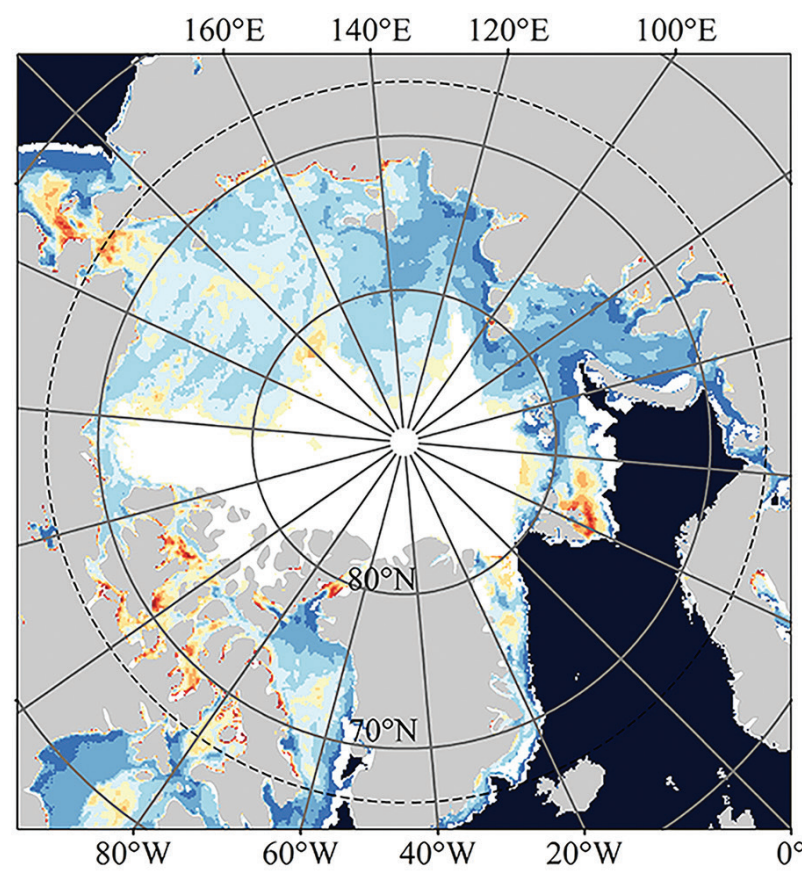

(b) NSIDC AMSR-E 2011.3.15

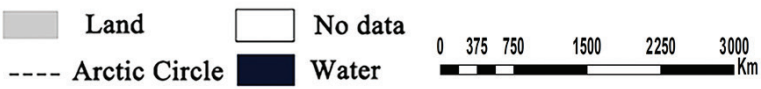

Fig. 2 Daily spatial distribution of snow depth on Arctic sea ice on 15 March 2011 calculated from (a) AMSR-E brightness temperature produced by UB, and (b) AMSR-E brightness temperature produced by NSIDC.

Since 2009, NASA has conducted the OIB programme for polar regions. Airborne snow radar was used to obtain snow-depth information on Arctic sea ice. A total of 74 days' OIB snow-depth data acquired between 2 April 2009 and 4 May 2016 (https://nsidc.org/icebridge/portal/ map) were used for comparison in this study (Fig. 3). After data preprocessing, the snow depth observed by OIB was averaged to different pixel sizes of $6.25 \mathrm{~km}, 12.5 \mathrm{~km}$ and $25 \mathrm{~km}$. It should be noted that the along-track resolution of OIB snow depth is $40 \mathrm{~m}$. Re-sampling preprocessing may cause some error with the actual situation because of the heterogeneous process; however, there is no better way to compare such data at different spatial resolutions. Following data preprocessing, the OIB snow depths were compared with the remote-sensed snow-depth products.

The IMB snow depths used for comparison were downloaded from the CRREL website (http://imb-crreldartmouth.org/results/) (Perovich et al. 2019). The buoys are equipped with downward and upward sounders to measure the interface of air-snow and ice-water, allowing the estimation of snow depth and sea-ice thickness (Richter-Menge et al. 2006; Blanchard-Wrigglesworth et al. 2018).
Considering the data quality and the space-time coverage of the IMB data, 76 buoys were used during 2002-2017 to derive snow depth on Arctic sea ice for comparison in this study (Fig. 4). Consistent with how Lee, Sohn \& Kummerow (2018) describe the buoy data quality, we also found some abnormal points, which we deleted on the basis of the Pauta criterion ( $3 \sigma$ criterion) and the visual interpretation method. The data synthesizing processing of the IMB snow depths was the same as for the OIB data.

In summary, four PM remote-sensing snow-depth products on Arctic sea ice, which were acquired from three organizations, were compared. The snow-depth observational data by the airborne snow radar and ice mass-balance buoys were also considered for comparison and validation. The corresponding parameters are summarized in Table 1 .

\section{Statistical and comparative analysis methods}

To compare the difference of different snow-depth products, as well as to evaluate them with respect to field observations (OIB and IMB), three statistics were 


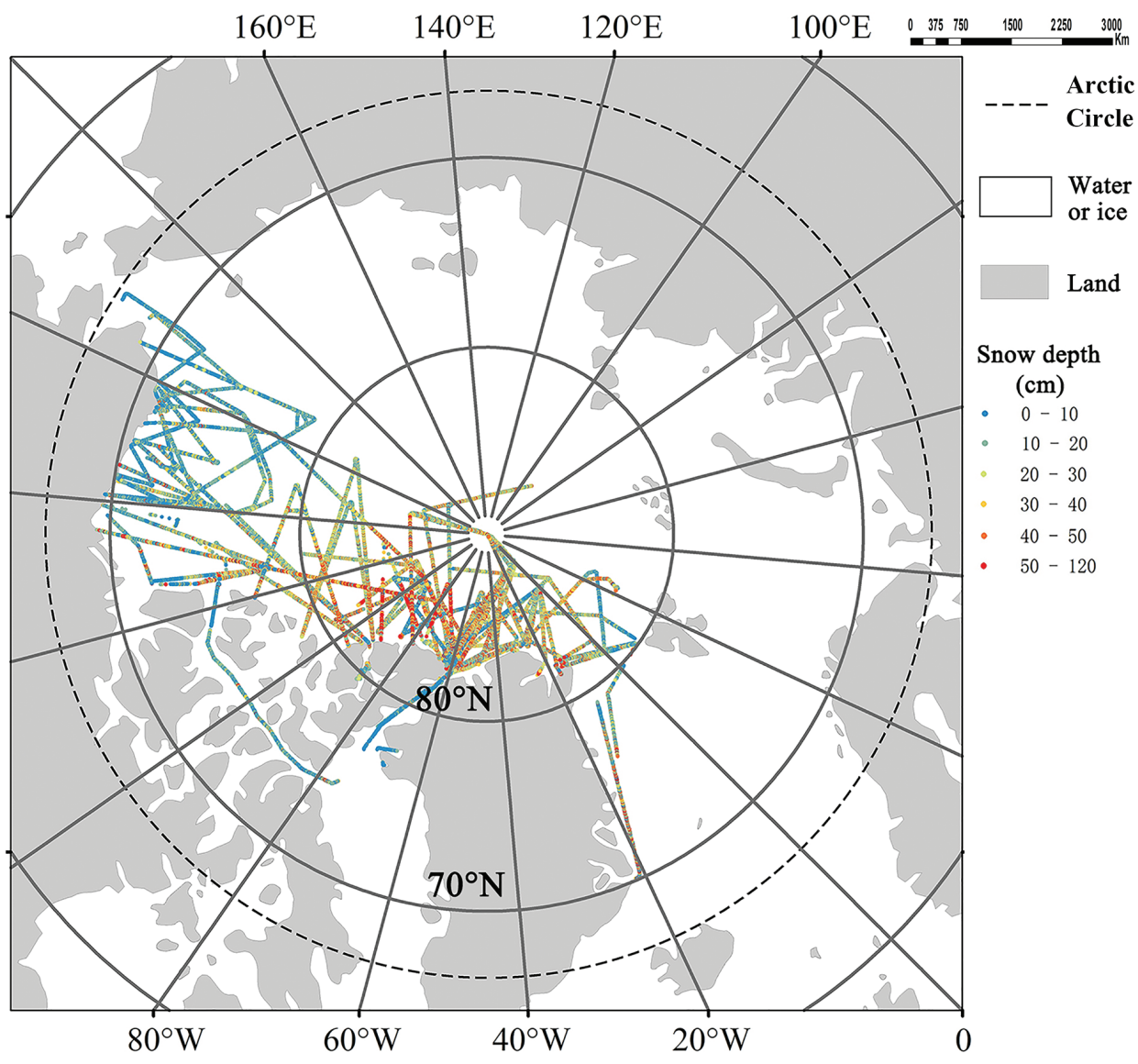

Fig. 3 Trajectory of OIB snow-depth measurements on Arctic sea ice from 2009 to 2016.

applied in this study. They are the bias, the MAD and the RMSD, which are calculated according to the following equations (Ouma et al. 2012).

$$
\begin{aligned}
\text { bias } & =\frac{\sum_{i=1}^{n}\left(X_{i}-Y_{i}\right)}{n}, \\
\mathrm{MAD} & =\frac{\sum_{i=1}^{n}\left|X_{i}-Y_{i}\right|}{n}, \\
\mathrm{RMSD} & =\sqrt{\frac{\sum_{i=1}^{n}\left(X_{i}-Y_{i}\right)^{2}}{n}},
\end{aligned}
$$

where $X_{\mathrm{i}}$ is the snow depth from one product based on PM measurements, $y_{i}$ is another snow-depth estimation from other products or field snow-depth measurements (OIB or IMB measurements of overlapping pixels) and $n$ is the number of statistical pixels.

\section{Results}

\section{Comparing UB SSMIS and NASA SSM/I snow-depth products}

Comparison of the time series snow depths from the UB SSMIS and NASA SSM/I products is shown in Fig. 5. The UB SSMIS snow-depth product is missing data from May to September 2013. On the other hand, the UB SSMIS product provides snow-depth data from October 2012 to October 2013, while the NASA SSM/I product doesn't do the same. The total overlapping coverage of these two snow-depth products is 624 days. The MAD and RMSD values of these two products during the overlapping period are small (less than $4 \mathrm{~cm}$ ). The differences between the UB SSMIS and NASA SSM/I products are small from December 2011 to May 2012 and from December 2013 to April 2014. However, the differences between them are relatively large for the periods of September 2011 to December 2011, July 2012 to October 2012 and October 2013 to December 2013. The largest difference between 


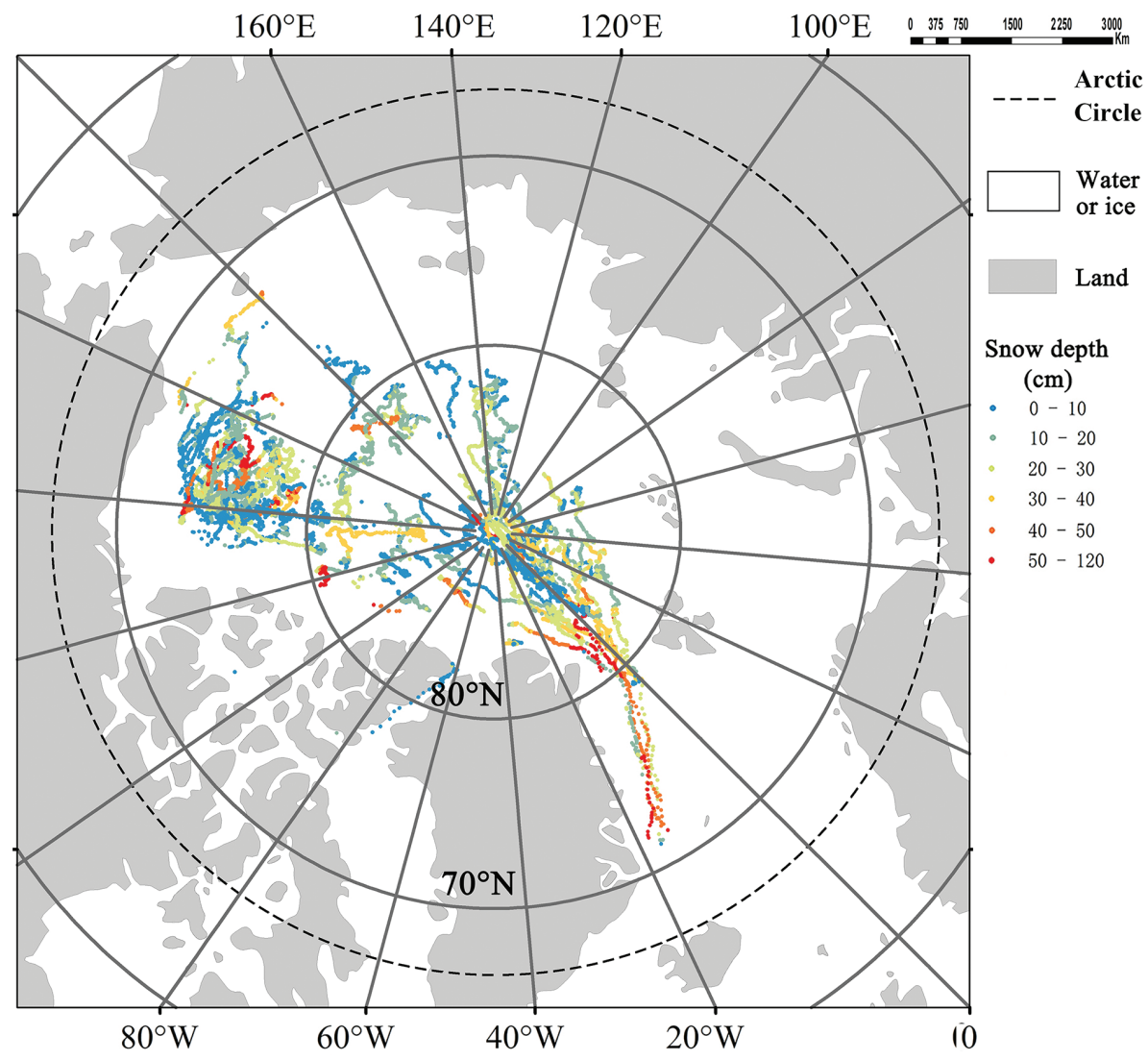

Fig. 4 Trajectory of IMB snow-depth measurements on Arctic sea ice from 2002 to 2017.

Table 1 Information of the four snow-depth products and the Operation Ice Bridge (OIB) and Ice Mass-Balance Buoy (IMB) snow depths used in this study.

\begin{tabular}{lllllc}
\hline Data & $\begin{array}{l}\text { Temporal } \\
\text { resolution }\end{array}$ & $\begin{array}{c}\text { Spatial } \\
\text { resolution }\end{array}$ & $\begin{array}{c}\text { Time coverage } \\
\text { (year. month. day) }\end{array}$ & Sensor & $\begin{array}{c}\text { Sea-ice concentration } \\
\text { algorithm }\end{array}$ \\
\hline UB AMSR-E & 1 day & $6.25 / 12.5 \mathrm{~km}$ & $2002.6 .1-2011.10 .04$ & AMSR-E & ASI \\
UB SSMIS & 1 day & $6.25 \mathrm{~km}$ & $2011.3 .8-2014.4 .15$ & SSMIS & ASI \\
NSIDC AMSR-E & 1 day & $12.5 \mathrm{~km}$ & $2002.6 .1-2011.10 .4$ & AMSR-E & NT2 \\
NASA SSM/I & 1 day & $25 \mathrm{~km}$ & $1987.11 .3-2017.2 .28$ & SSM/l & NT \\
OIB & 1 day & $40 \mathrm{~m}$ & $2002.4 .27-2017.5 .16$ & Snow radar & - \\
IMB & $2 / 4 / 8$ hours & - & $2009.4 .2-2016.5 .4$ & Sounder & - \\
\hline
\end{tabular}

UB SSMIS and NASA SSM/I appears on 20 August 2012, with the value of $16 \mathrm{~cm}$. It is inferred that these two products are similar from January to March, when the snow depth changes gradually. From June to September, when the snow depth changes sharply, these two products have obvious differences.

\section{Comparing UB AMSR-E and NSIDC AMSR-E snow-depth products}

Figure 6 shows the time series of the AMSR-E snow depth produced by UB and NSIDC. It can be seen that these products have nearly 10 years of available snow-depth observations. Moreover, the data continuity of AMSR-E snow-depth products is better than the SSMIS snowdepth products, as explained earlier. As for the respective daily snow-depth estimates from UB and NSIDC, the UB AMSR-E snow depths are significantly greater than those from the NSIDC AMSR-E product. The RMSD value of these two products during the overlapping period was $12.6 \mathrm{~cm}$. The largest difference of $29.57 \mathrm{~cm}$ of these two snow-depth products appeared on 2 September 2002. The larger difference usually occurs around September, which happens to be the period when the snow depth changes 


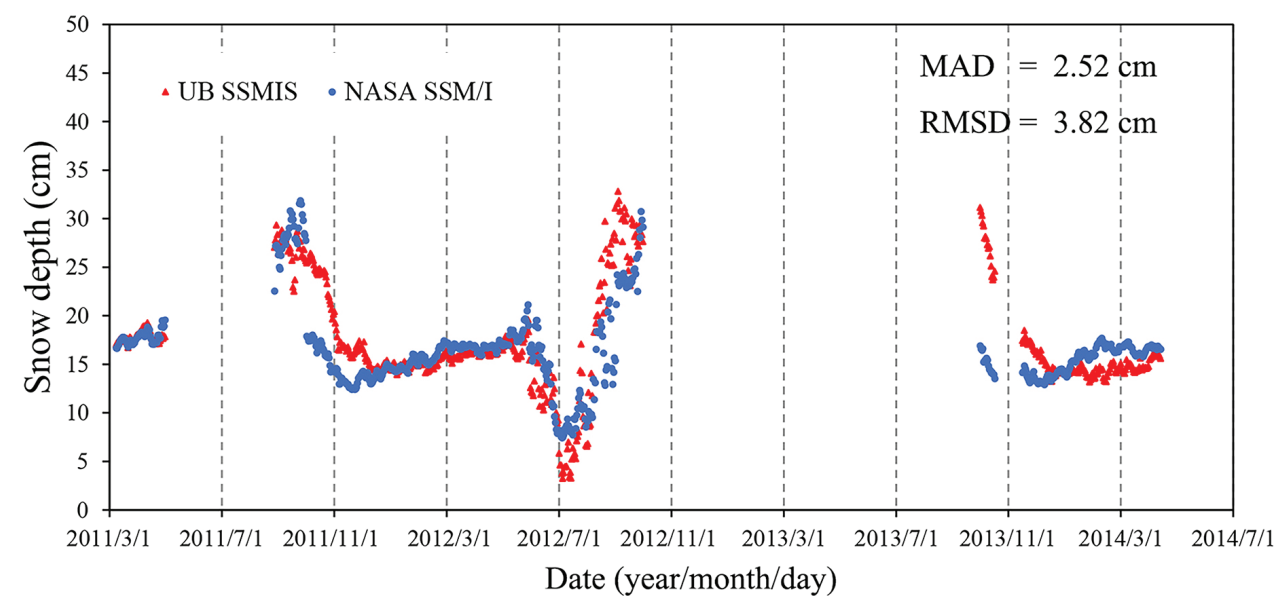

Fig. 5 Comparison of the UB SSMIS and NASA SSM/I daily snow depths from March 2011 to April 2014.

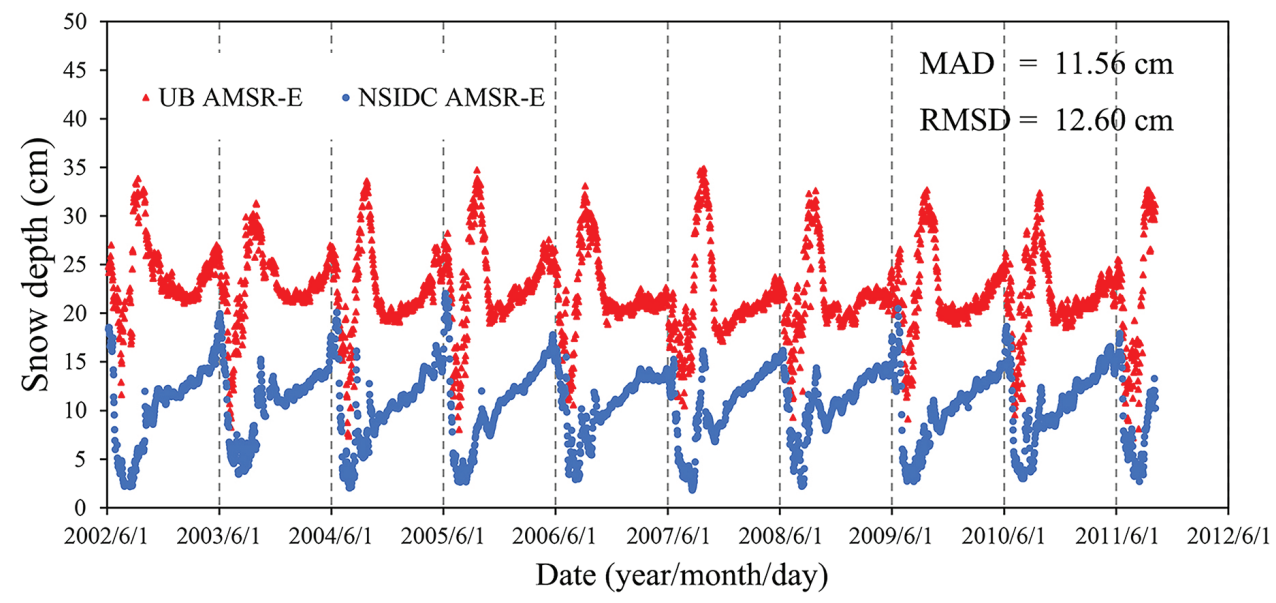

Fig. 6 Comparison of the UB AMSR-E and NSIDC AMSR-E daily snow depths from June 2002 to October 2011.

more sharply (Sato \& Inoye 2018). However, these two snow-depth products display similar periodic variations.

\section{Comparing the four PM remote-sensing snow- depth products}

Figure 7 shows the comparison of four PM remotesensing snow-depth products used in this study during the common overlapping period. Since the time coverage of different PM data sets is inconsistent, the period during which they overlap is not very long-from 9 March 2011 to 4 October 2011 -and no data were available during summer. The snow depth of the four PM products varies in a similar trend, especially from March to May. During the period of rapid sea-ice growth (from September to October), the difference between snow-depth products increases markedly. In terms of the average snow depth of the four PM products, the value of the UB AMSR-E snow depth is the highest, while the value of NSIDC AMSR-E snow depth is the lowest.

\section{Comparing the snow-depth products against OIB and IMB observational snow depths}

We compared the UB AMSR-E, UB SSMIS, NSIDC AMSR-E and NASA SSM/I snow depths with the OIB snow depths; the scatter plots are shown in Fig. 8. It is observed that there are great differences in the number of the overlapping pixels for the four snow-depth products compared with 74-day OIB snow depths during 2009-2016, as explained earlier. There are 6371 overlapping pixels between the UB SSMIS snow-depth product and the OIB snow depths, while there are only 615 overlapping pixels between the NSIDC AMSRE-E snow-depth 


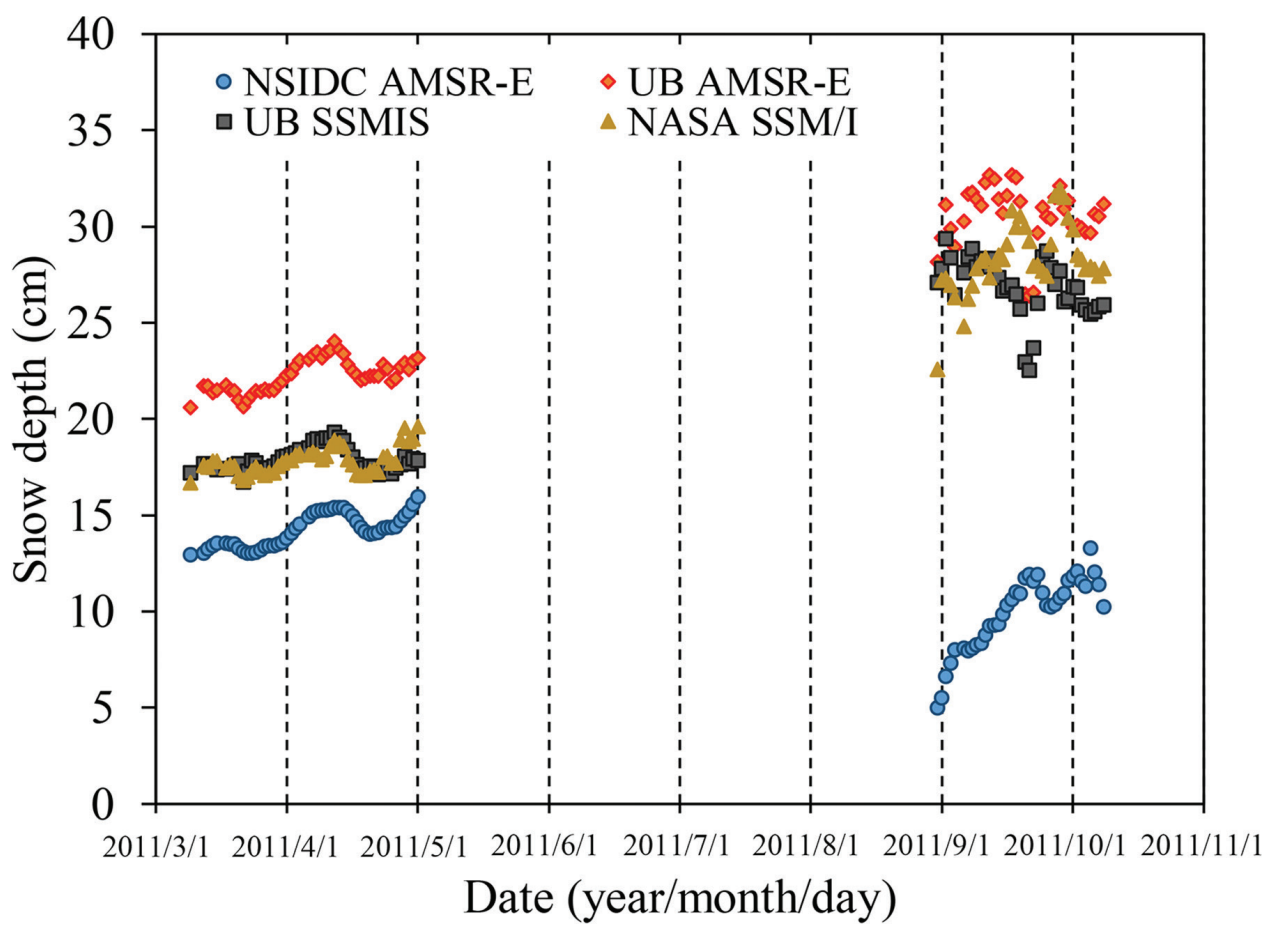

Fig. 7 Comparison of four PM daily snow depths from March 2002 to October 2011.

product and the OIB snow depths. For the overlapping pixels, we found that the snow depths calculated from AMSR-E and SSMIS produced by UB are significantly larger than the OIB snow depths, while the snow depths from NSIDC AMSR-E and NASA SSM/I products are closer to the OIB snow depths. The accuracy of the NSIDC AMSR-E product is the highest among the four snow-depth products, with a bias of $0.6 \mathrm{~cm}$ against the OIB snow depths. Meanwhile, the accuracy of the UB SSMIS snow-depth product is closer to that of the UB AMSR-E snow-depth product, but lower than that of NASA SSM/I snow-depth product.

The snow depths measured by IMB during 2002-2017 were also used to compare with the four PM snow-depth products (Table 2). The number of overlapping pixels between UB AMSR-E, UB SSMIS, NSIDC AMSR-E and NASA SSM/I snow-depth products and the IMB snow depth is 3549, 3535, 1319 and 1911 respectively. This confirms that the NSIDC AMSR-E snow-depth product has the minimum overlapping pixels but the highest accuracy among the four snow-depth products. Moreover, the accuracy of NASA SSM/I snow depth is higher than that of the UB's two snow-depth products when evaluated against IMB snow depths. Although the UB AMSR-E and UB SSMIS have a similar number of overlapping pixels, the accuracy of the UB SSMIS snow depth is better than that of UB AMSR-E.
We also compared UB SSMIS, UB AMSR-E and NSIDC AMSR-E snow-depth products with the OIB and IMB snow depths during the common overlapping period (68 pixels for OIB and 191 pixels for IMB). Figure 9 shows that the MAD and RMSD values for the UB AMSR-E and SSMIS snow depths are significantly lower than that presented in Fig. 8 and Table 2. Moreover, the accuracy of the NSIDC AMSR-E snow-depth product is higher than that of the UB AMSR-E.

\section{Spatial differences among the UB AMSR-E, NSIDC AMSR-E and NASA SSM/I snow-depth products}

Figure 10 shows the snow-depth spatial distribution from UB AMSR-E, NSIDC AMSR-E and NASA SSM/I product (taking March and April in 2011 as examples). It is seen that the spatial distribution of snow depth from NSIDC AMSR-E and NASA SSM/I is similar, while the UB AMSR-E snow depths are quite different from them. Moreover, snow-depth data are available for the central part of the Arctic Ocean and the Beaufort Sea for the UB AMSR-E snow-depth product, while there are no data for NSIDC AMSR-E nor for the NASA SSM/I snowdepth products in those regions. There are smaller snowdepth differences in the Kara Sea and Barents Sea among snow-depth products, while UB AMSR-E snow depths are significantly higher than those from NSIDC AMSR-E 

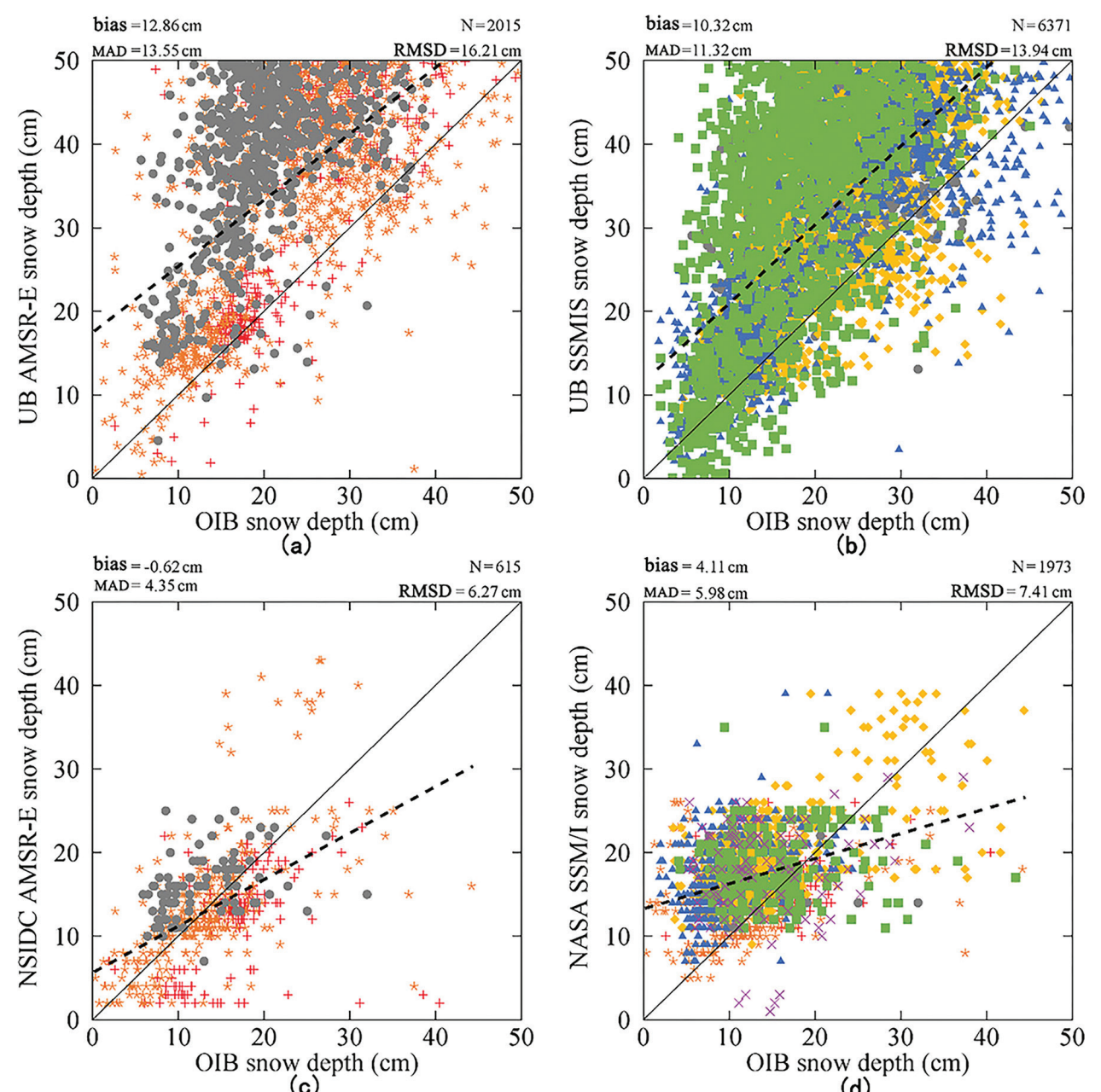

$+2009 * 2010 \bigcirc 2011$

$2012 \Delta 2014$

(d)

Fig. 8 Comparison of different snow-depth products against OIB snow depths: (a) UB AMSR-E versus OIB; (b) UB SSMIS versus OIB; (c) NSIDC AMSR-E versus OIB; and (d) NASA SSM/I versus OIB. N refers to the number of the overlapping pixels between the remote-sensing snow-depth product and the OIB snow depths during 2009-2016. In each plot, the black line is the one-to-one fitting line and the dashed line is the regression line of the remote-sensing snow-depth product and the OIB snow depth.

Table 2 Comparison of different snow-depth products against Ice Mass-Balance Buoy (IMB) snow depths during 2002-2017.

\begin{tabular}{lcccc}
\hline Statistics & $\begin{array}{c}\text { UB AMSR-E } \\
\text { vs IMB }\end{array}$ & $\begin{array}{c}\text { UB SSMIS } \\
\text { vs IMB }\end{array}$ & $\begin{array}{c}\text { NSIDC AMSR-E } \\
\text { vs IMB }\end{array}$ & $\begin{array}{c}\text { NASA SSM/I } \\
\text { vs IMB }\end{array}$ \\
\hline bias $(\mathrm{cm})$ & -12.52 & -8.16 & -1.71 & -4.04 \\
MAD $(\mathrm{cm})$ & 16.45 & 14.31 & 10.11 & 11.03 \\
$\operatorname{RMSD}(\mathrm{cm})$ & 20.04 & 17.05 & 12.54 & 14.81 \\
\hline
\end{tabular}

and NASA SSM/I snow depths in the East Siberian Sea and the Laptev Sea. Generally, these three products show approximately the same spatial distribution of high and low snow depths, with all three presenting the snow depth in the central Arctic Ocean and the Laptev Sea as higher than that of other sea regions.

\section{Discussion}

Considering the accuracy of these four PM snow-depth products, Markus \& Cavalieri (1998) reported a bias of $3.5 \mathrm{~cm}$ between SSM/I-derived snow depths and shipbased snow-depth observations from August 1993 to September 1993 in the Bellingshausen Sea and the Amundsen Sea in the Antarctic. In this paper, we arrived at a bias of $4.1 \mathrm{~cm}$ between the NASA SSM/I snow depths and OIB observations, which is closer to that of Markus 
\& Cavalieri (1998). Brucker \& Markus (2013) validated AMSR-E snow depths using OIB snow-depth measurements from 2009 and 2011, with a MAD value of $7 \mathrm{~cm}$. Our results show a MAD value of $4.35 \mathrm{~cm}$ when NSIDC AMSR-E snow depths are compared with the OIB snow depths during 2009-2016.

According to our comparison of the four PM snowdepth products with the OIB and IMB snow depths, as explained earlier, the accuracy of the UB snow-depth products is lower than that of NSIDC and NASA snowdepth products for the same sensor whether the comparison is made with OIB or IMB snow depths. Some scatters parallel to the $y$-axis can be found in Fig. 9 (d-f). This parallel feature is formed by the corresponding similar IMB snow-depth records to several PM records with diverse snow depths. The smaller the length of the parallel segment, the closer the PM snow depth to the in situ IMB measurements. UB SSMIS and NSIDC AMSR-E snow-depth products are more accurate than UB AMSR-E as shown by the shorter parallel segment, which is consistent with statistical results. It is seen that these four
PM products have relatively small biases when compared with the OIB snow depths than when compared with the IMB snow depths. IMBs are usually deployed on level of multi-year ice and result in more thick snow-depth information on Arctic multi-year sea ice (Richter-Menge et al. 2006), while the OIB snow depths are obtained by the airborne snow radar and contain more thin snow depths on Arctic first-year sea ice. It should be noted that the MAD values between OIB snow depth and in situ field measurements are less than $1 \mathrm{~cm}$ (Farrell et al. 2011). This indicates that OIB snow depth is accurate enough to be snow-depth validation data (Kurtz \& Farrell 2011). Since the snow-depth retrieval algorithm of the PM has more uncertainties on multi-year sea ice than the first-year sea ice (Markus \& Cavalieri 1998; Perovich et al. 2007), the snow depths of these four products are expected to be closer to the OIB measured snow depths than to the IMB snow depths.

The NSIDC AMSR-E and NASA SSM/I products are the five-day snow-depth synthesized processing results, while UB AMSR-E and UB SSMIS snow-depth products

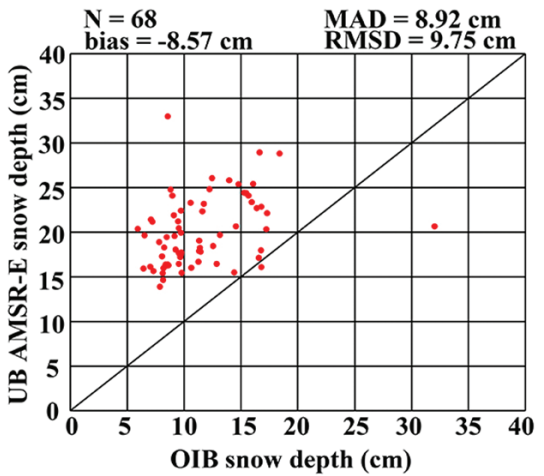

(a)

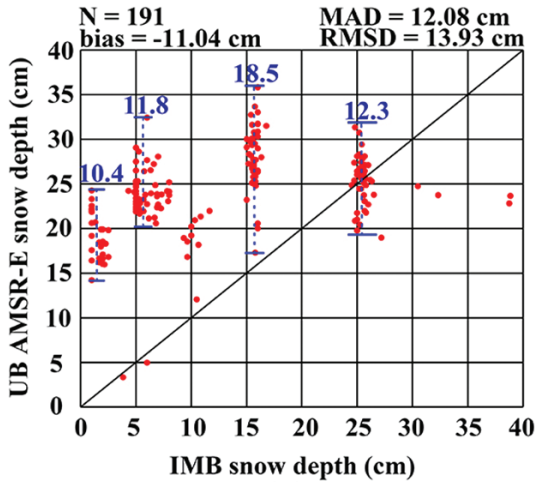

(d)

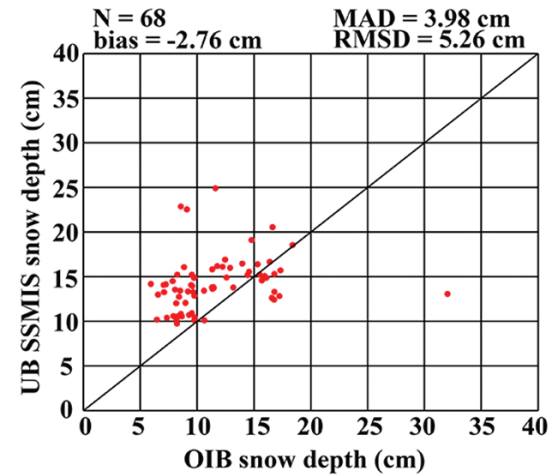

(b)

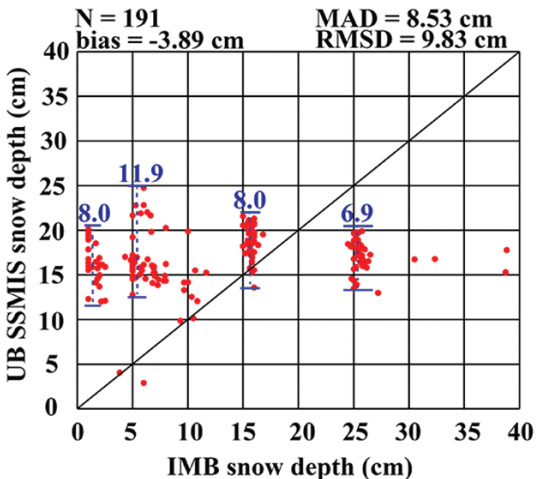

(e)

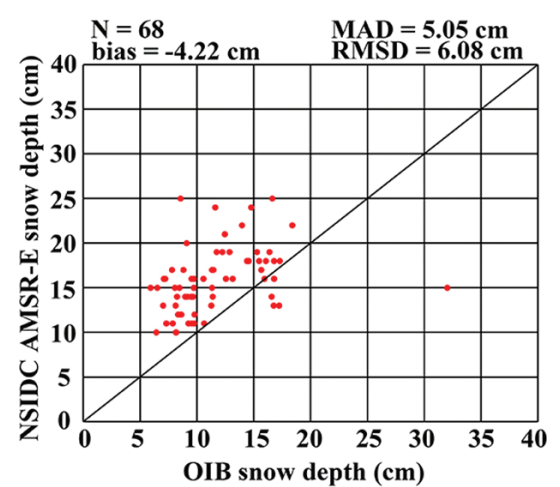

(c)

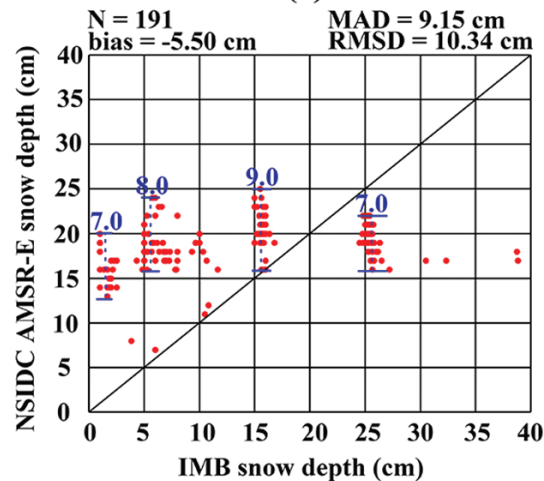

(f)

Fig. 9 The scatter plots of PM snow-depth products with OIB and IMB snow depths: (a) UB AMSR-E versus OIB; (b) UB SSMIS versuS OIB; (c) NSIDC AMSR-E versus OIB; (d) UB AMSR-E versus IMB; (e) UB SSMIS versus IMB; and (f) NSIDC AMSR-E versus IMB. N refers to the number of common overlapping pixels between the remote-sensing snow-depth product and the OIB or IMB snow depths. In each plot, the black line is the one-to-one fitting line and in (d) - (f) the blue numbers and short horizontal blue lines are the differences in snow depth in each parallel distribution scatter. 
provided snow depth on a specific day. This could partly explain the difference between them. Different sea-ice concentration algorithms used for snow-depth retrieval would also cause differences among different snow-depth products (Kurtz \& Farrell 2011). It should be noted that the UB AMSR-E and UB SSMIS snow-depth products use the ASI sea-ice concentration algorithm, while the NSIDC AMSR-E and NASA SSM/I snow-depth products use seaice concentration inputs based on NT2 and NT algorithms respectively (Markus \& Cavalieri 1998; Comiso et al. 2003; Spreen et al. 2008).

All the four snow-depth products present similar periodic changes and spatial distribution on Arctic sea ice, but they differ with regard to data accuracy, and there are local differences in some regions. It should be noted that the snow depths from all these products derived from PM remote-sensing data are indeterminate under wet snow conditions and in multi-year sea-ice zones (Markus \& Cavalieri 1998; Perovich et al. 2007).

\section{Conclusions}

This study compared four snow-depth products on Arctic sea ice based on three PM remote sensing sensors produced by three organizations. During the overlapping period, the average snow-depth difference between NASA SSM/I and UB SSMIS snow-depth products was

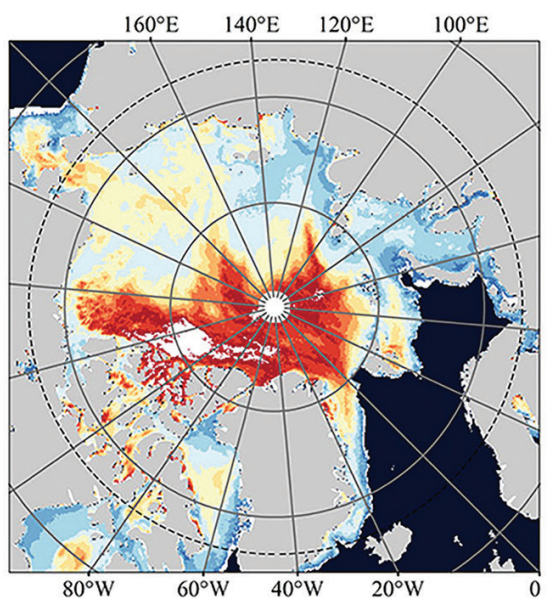

(a) UB AMSR-E 2011.3

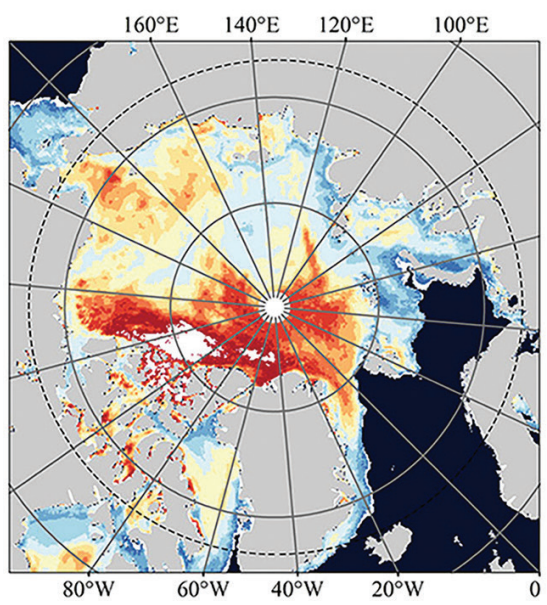

(d) UB AMSR-E 2011.4

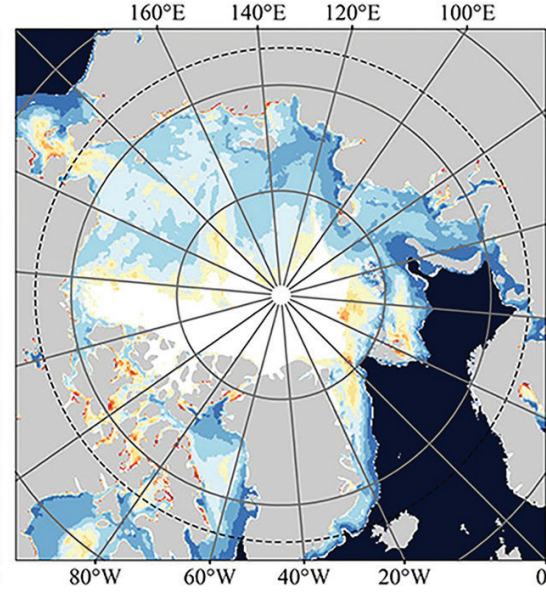

(b) NSIDC AMSR-E 2011.3

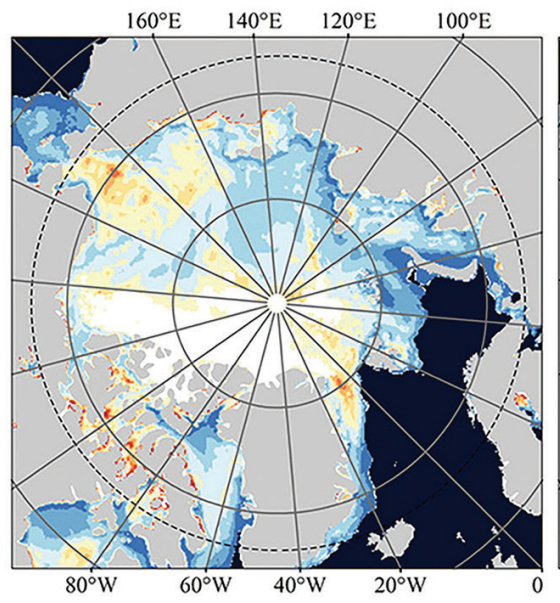

(e) NSIDC AMSR-E 2011.4

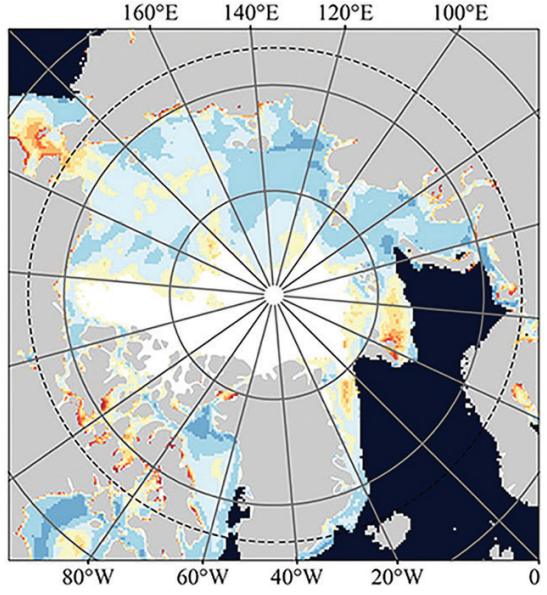

(c) NASA SSM/I 2011.3

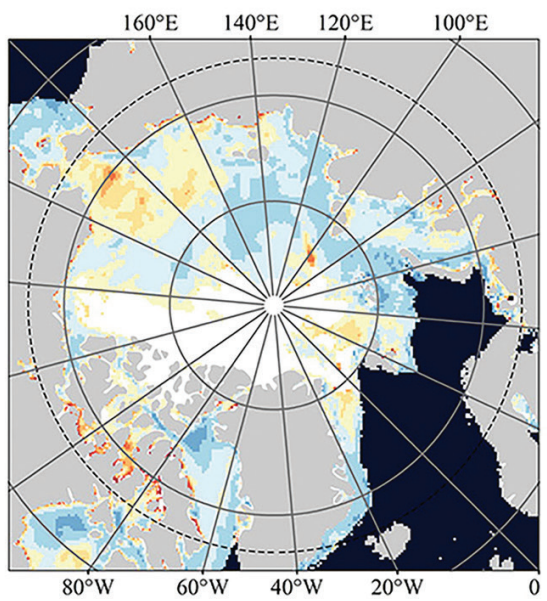

(f) NASA SSM/I 2011.4

Fig. 10 UB AMSR-E, NSIDC AMSR-E and NASA SSM/I monthly average snow-depth distribution and their spatial difference in March 2011 and April 2011: (a), (b) and (c) are the monthly average snow-depth distribution of UB AMSR-E, NSIDC AMSR-E and NASA SSM/I in March 2011; (d), (e) and (f) are the monthly average snow-depth distribution of UB AMSR-E, NSIDC AMSR-E and NASA SSM/l in April 2011; (g), (h) and (i) are their spatial snow-depth differences in March 2011; and (j), (k) and (I) are their spatial snow-depth differences in April 2011. 


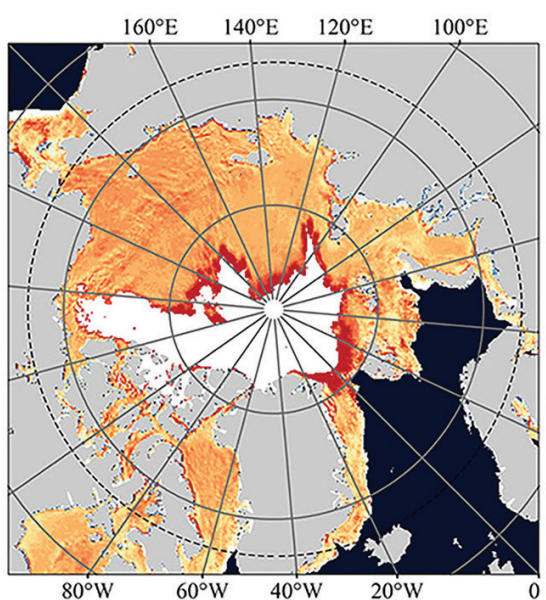

(g) UB - NSIDC 2011.3

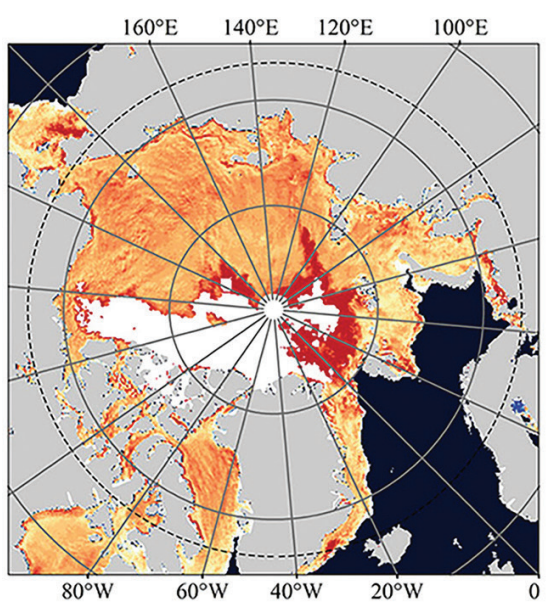

(j) UB - NSIDC 2011.4

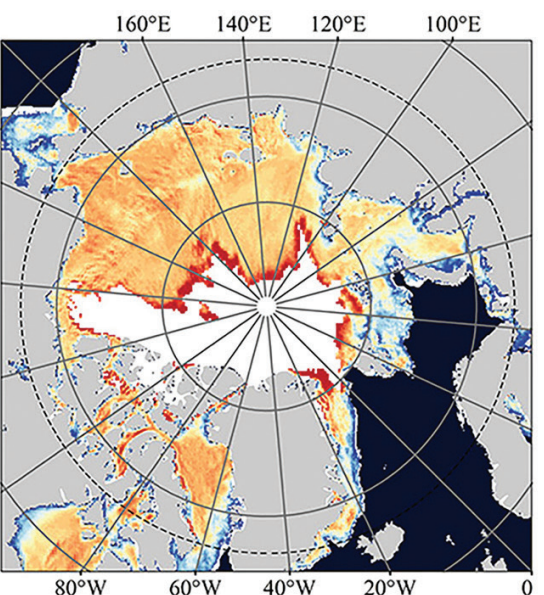

(h) UB-NASA 2011.3

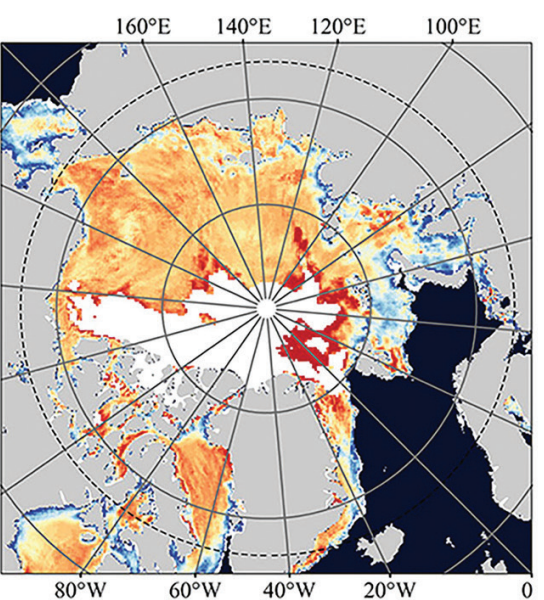

(k) UB - NASA 2011.4

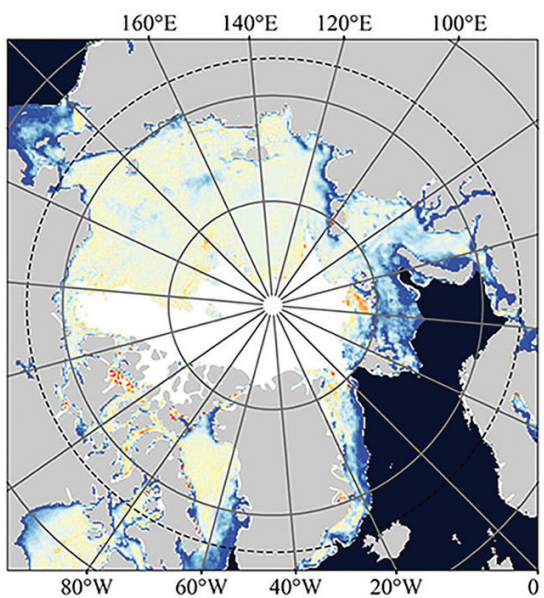

(i) NSIDC - NASA 2011.3

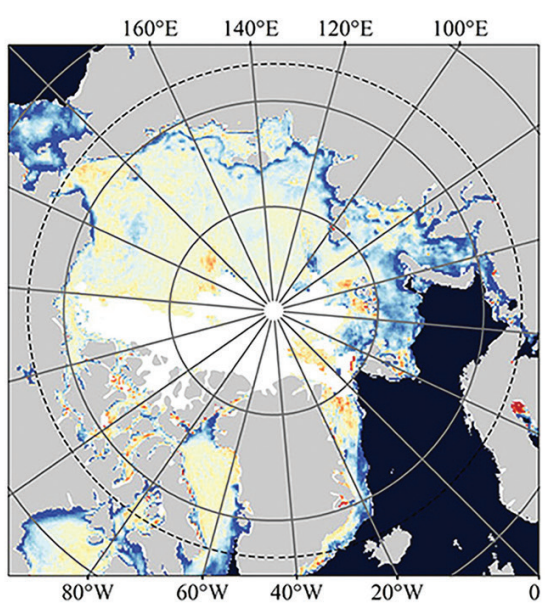

(1) NSIDC - NASA 2011.4

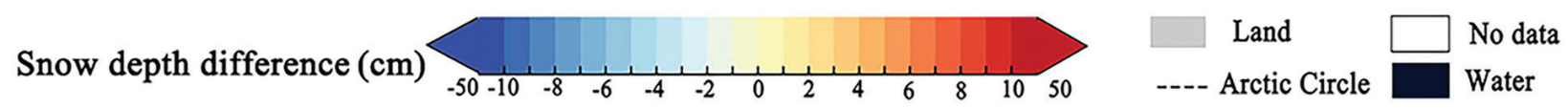

Fig. 10 (Continued) UB AMSR-E, NSIDC AMSR-E and NASA SSM/I monthly average snow-depth distribution and their spatial difference in March 2011 and April 2011: (a), (b) and (c) are the monthly average snow-depth distribution of UB AMSR-E, NSIDC AMSR-E and NASA SSM/I in March 2011; (d), (e) and ( $f$ ) are the monthly average snow-depth distribution of UB AMSR-E, NSIDC AMSR-E and NASA SSM/I in April 2011; (g), (h) and (i) are their spatial snow-depth differences in March 2011; and (j), (k) and (I) are their spatial snow-depth differences in April 2011.

less than $1 \mathrm{~cm}$, while the average snow-depth difference between UB AMSR-E and NSIDC AMSR-E was as much as $10 \mathrm{~cm}$. During the time of the year when snow depth changes sharply, the snow-depth products showed large difference. Our analysis shows that the NSIDC AMSR-E product is a good choice for users because it had the highest accuracy. UB AMSR-E had the lowest accuracy among the four products that we compared. All the products showed the same spatial distribution of high and low snow depths, with the snow depth higher in the central part of the Arctic Ocean and the Laptev Sea than in other sea areas. It is hoped that this comparative would facilitate the better application of these snow-depth products, and would contribute to improving the future studies of Arctic sea ice and climate change.

\section{Acknowledgements}

The authors would like to thank the NASA, the NSIDC and the UB for providing SSM/I, SSMIS and AMSR-E snow-depth data. The authors acknowledge NASA and CRREL for providing OIB and IMB snow-depth data for validation. Comments from anonymous referees and the subject editor are also gratefully appreciated. 


\section{Authors' contributions}

QJ and XP designed the experiments, and CZ wrote the article under the supervision of QJ; CZ and CL analysed the experimental data; QJ and JS contributed to the preparation of the compared results. All authors were involved in the revision of the article and the discussion of the results.

\section{Disclosure statement}

The authors report no conflict of interest.

\section{Funding}

The authors acknowledge joint support by the National Key Research and Development Program of China (2016YFC1402704, 2017YFA0603104) and the National Natural Science Foundation of China (41576188, $41606215)$.

\section{References}

Blanchard-Wrigglesworth E., Webster M.A., Farrell S.L. \& Bitz C.M. 2018. Reconstruction of snow on Arctic sea ice. Journal of Geophysical Research-Oceans 123, 3588-3602, doi: 10.1002/2017JC013364.

Blazey B.A., Holland M.M. \& Hunke E.C. 2013. Arctic Ocean sea ice snow depth evaluation and bias sensitivity in CCSM. The Cryosphere 7, 1887-1900, doi: 10.5194/ tc-7-1887-2013.

Brucker L. \& Markus T. 2013. Arctic-scale assessment of satellite passive microwave-derived snow depth on sea ice using Operation IceBridge airborne data. Journal of Geophysical Research-Oceans 118, 2892-2905, doi: 10.1002/ jgrc. 20228.

Comiso J.C. 2012. Large decadal decline of the Arctic multi-year ice cover. Journal of Climate 25, 1176-1193, doi: 10.1175/JCLI-D-11-00113.1.

Comiso J.C., Cavalieri D.J. \& Markus T. 2003. Sea ice concentration, ice temperature, and snow depth using AMSR-E data. IEEE Transactions on Geoscience and Remote Sensing 41, 243-252, doi: 10.1109/TGRS.2002.808317.

Farrell S.L., Kurtz N., Connor L.N., Elder B.C. \& Sonntag J.G. 2011. A first assessment of ice bridge snow and ice thickness data over Arctic sea ice. IEEE Transactions on Geoscience and Remote Sensing 50, 2098-2111, doi: 10.1109/ TGRS.2011.2170843.

Kurtz N.T. \& Farrell S. L. 2011. Large-scale surveys of snow depth on Arctic sea ice from Operation IceBridge. Geophysical Research Letters 38, L20505, doi: 10.1029/2011GL049216.

Kwok R. \& Cunningham G.F. 2008.ICESat over Arctic sea ice: estimation of snow depth and ice thickness. Journal of Geophysical Research-Oceans 113, C08010, doi: 10.1029/2008JC004753.
Lei R., Tian-Kunze X., Li B., Heil P., Wang J., Zeng J. \& Tian Z. 2017. Characterization of summer Arctic sea ice morphology in the $135^{\circ}-175^{\circ} \mathrm{W}$ sector using multi-scale methods. Cold Regions Science and Technology 133, 108-120, doi: 10.1016/j.coldregions.2016.10.009.

Lee S.M., Sohn B.J. \& Kummerow C. 2018. Long-term Arctic snow/ice interface temperature from special sensor for microwave imager measurements. Remote Sensing 10(11), article no. 1795, doi: 10.3390/rs10111795.

Lee S.M., Sohn B.J. \& Shi H. 2018. Impact of ice surface and volume scatterings on the microwave sea ice apparent emissivity. Journal of Geophysical Research-Atmospheres 123, 9220-9237, doi: 10.1029/2018JD028688.

Mäkynen M. \& Similä M. 2015. Thin ice detection in the Barents and Kara seas with AMSR-E and SSMIS radiometer data. IEEE Transactions on Geoscience and Remote Sensing 53, 5036-5053, doi: 10.1109/TGRS.2015.2416393.

Markus T. \& Cavalieri D.J. 1998. Snow depth distribution over sea ice in the Southern Ocean from satellite passive microwave data. In M.O. Jeffries (eds.): Antarctic sea ice: physical processes, interactions, and variability. Vol. 74. Pp. 19-39. Washington, DC: American Geophysical Union.

Maslanik J., Stroeve J., Fowler C. \& Emery W. 2011. Distribution and trends in Arctic sea ice age through spring 2011. Geophysical Research Letters 38, L13502, doi: 10.1029/2011GL047735.

Nghiem S.V., Rigor I.G., Perovich D.K., Clemente-Colón P., Weatherly J.W. \& Neumann G. 2007. Rapid reduction of Arctic perennial sea ice. Geophysical Research Letters, L19504, doi: 10.1029/2007GL031138.

Ogawa F., Keenlyside N., Gao Y., Koenigk T., Yang S., Suo, L., Wang T., Gastineau G., Nakamura T., Cheung H.N., Omrani N.E., Ukita J. \& Semenov V. 2018. Evaluating impacts of recent Arctic sea ice loss on the northern hemisphere winter climate change. Geophysical Research Letters 45, 3255-3263, doi: 10.1002/2017GL076502.

Ouma Y.O., Owiti T., Kipkorir E., Kibiiy J. \& Tateishi R. 2012. Multitemporal comparative analysis of trmm-3b42 satellite-estimated rainfall with surface gauge data at basin scales: daily, decadal and monthly evaluations. International Journal of Remote Sensing 33, 7662-7684, doi: 10.1080/01431161.2012.701347.

Perovich D.K., Light B., Eicken H., Jones K.F., Runciman K. \& Nghiem S.V. 2007. Increasing solar heating of the Arctic Ocean and adjacent seas, 1979-2005: attribution and role in the ice-albedo feedback. Geophysical Research Letters 34, L19505, doi: 10.1029/2007GL031480.

Perovich D.K., Richter-Menge J.A. \& Polashenski C. 2019. Observing and understanding climate change: monitoring the mass balance, motion, and thickness of Arctic sea ice. Accessed on the internet at http://imb-crrel-dartmouth. org/results/ on 10 March 2018.

Riche F. \& Schneebeli M. 2013. Thermal conductivity of snow measured by three independent methods and anisotropy considerations. The Cryosphere, 217-227, doi: 10.5194/ tc-7-217-2013.

Richter-Menge J.A., Perovich D.K., Elder B.C., Claffey K., Rigor I. \& Ortmeyer M. 2006. Ice mass-balance buoys: a 
tool for measuring and attributing changes in the thickness of the Arctic sea-ice cover. Annals of Glaciology, 205-210, doi: 10.3189/172756406781811727.

Rostosky P., Spreen G., Farrell S.L., Frost T., Heygster G. \& Melsheimer C. 2018. Snow depth retrieval on Arctic sea ice from passive microwave radiometers-Improvements and extensions to multiyear ice using lower frequencies. Journal of Geophysical Research-Oceans 123, 7120-7138, doi: 10.1029/2018JC014028.

Sato K. \& Inoue J. 2018. Comparison of Arctic sea ice thickness and snow depth estimates from CFSR with in situ observations. Climate Dynamics 50, 289-301, doi: 10.1007/ s00382-017-3607-z.

Spreen G., Kaleschke L. \& Heygster G. 2008. Sea ice remote sensing using AMSR-E 89-GHz channels. Journal of Geophysical Research-Oceans 113, C02S03, doi: 10.1029/2005 JC003384.

Stocker T.F., Qin D., Plattner G.K., Tignor M., Allen S.K., Boschung J., Nauels A., Xia Y., Bex B. \& Midgley B. (eds.) 2013. Climate change 2013. The physical science basis.
Contribution of Working Group I to the fifth assessment report of the Intergovernmental Panel on Climate Change. Cambridge: Cambridge University Press.

Stroeve J.C., Kattsov V., Barrett A., Serreze M., Pavlova T., Holland M. \& Meier W.N. 2012. Trends in Arctic sea ice extent from CMIP5, CMIP3 and observations. Geophysical Research Letters 39, L16502, doi: 10.1029/2012GL052676.

Warren S.G., Rigor I.G., Untersteiner N., Radionov V.F., Bryazgin N.N., Aleksandrov Y.I. \& Colony R. 1999. Snow depth on Arctic sea ice. Journal of Climate 12, 1814-1829, doi: 10.1175/1520-0442(1999)012<1814:SDOASI>2.0.CO;2. Webster M.A., Gerland S., Holland M., Hunke E., Kwok R., Lecomte O., Massom R., Perovich D.K. \& Sturm M. 2018. Snow in the changing sea-ice systems. Nature Climate Change 8, 946-953, doi: 10.1038/s41558-018-0286-7.

Webster M.A., Rigor I.G., Nghiem S.V., Kurtz N.T., Farrell S.L., Perovich D.K. \& Sturm M. 2014. Interdecadal changes in snow depth on Arctic sea ice. Journal of Geophysical Research-Oceans 119, 5395-5406, doi: 10.1002/2014 JC009985. 